\title{
VIBRATION ANALYSIS AND REPAIR PROCESS FOR THE VENTILATION SYSTEM FOR SMOKE DRAIN IN THE THERMAL POWER PLANT
}

UDC: $621.311 .22: 534.1$

Original scientific paper

https://doi.org/10.18485/aeletters.2018.3.1.7

\author{
Emir Nezirić ${ }^{1}$, Safet Isić ${ }^{1}$, Edin Džiho ${ }^{1}$ \\ 1"Džemal Bijedić" University of Mostar, Faculty of Mechanical Engineering, Bosnia and Herzegovina
}

\begin{abstract}
:
Vibrations are common phenomenon in the rotating machinery, which could carry important information about condition of the rotating machinery. All specific failures in rotating machinery have their own characteristics of the vibrations. By measuring and analysis of vibrations cause of increased vibrations could be determined. Since misalignment and rotating looseness have similar frequency spectrum characteristics, it is difficult to determine which one of the failures is present. When cause of increased vibrations is determined, it is possible to plan the future steps for the repairing and neutralising present cause of the possible failure.

Process of vibration analysis followed by present cause of increased vibration in rotating machinery repairing is presented in this paper through example on the ventilation system for smoke drain in the thermal power plant.
\end{abstract}

\section{ARTICLE HISTORY \\ Received 15.01.2018 \\ Accepted 03.03.2018 \\ Available 15.03.2018}

\section{KEYWORDS}

Vibration analysis, thermal power plant, ventilation system.

\section{INTRODUCTION}

Reliability of the thermal power plant as one of the mechanical systems is main goal of power producing companies, which causing continuous electricity production. Reliability is achieved when there are no unexpected failures of machines and when it is possible to predict time and cause of machine failure. With those predictions it is possible to plan a future stoppage and possible repairs in the machine system.

Most commonly used method for condition monitoring of the machines in the thermal power plant system is vibration analysis. By measuring frequency and amplitude of the machine vibrations it is possible to determine what is causing that vibration with frequency analysis and how much is machine moving with amplitude analysis.

After determination of main cause of increased vibrations, it is needed to plan future repairs and removal of vibration cause. Since the most loaded elements of rotating machines are the bearings and the couplings, repairs are mostly consisted of replacing those machine parts. Those repairs are mostly time-consuming and the power production is process of high importance, so sometimes it is needed to do some quick repairs to habilitate machine for short-time usage, until repairing process is suitable to carry out.

Process of vibration analysis followed by present cause of increased vibration in rotating machinery repairing is presented in this paper through the example on the ventilation system for smoke drain in the coal-heated thermal power plant Kakanj, Bosnia \& Herzegovina.

\section{VIBRATION ANALYSIS}

Vibrations are common phenomenon in rotating machinery, which could carry important information about condition of the rotating machinery. All specific failures in rotating machinery have their own characteristics of vibrations. Measurements and analysis of the vibratory behaviour of the system and vibration changes leads to the detection of problems and faults $[1,2]$. 
Most common failure of rotating machinery is misalignment of shafts connected by couplings [1]. Misalignment could be parallel or angular. In practice, misalignment is usually combination of parallel and angular misalignment $[1,3,4]$. In frequency spectrum of severe misalignment are present orders of rotational frequency $(1 X, 2 X, \ldots)$ even up to $10 \mathrm{X}$ in radial and axial direction.

Other failure with similar characteristics is rotational looseness who could be described as appearance of the clearance between rotating shaft, bearing or housing. Frequency spectrum also contain orders of rotational frequency $(1 X, 2 X, \ldots)$ which could also go above 10X [5].

If it is impossible to determine which failure is causing the increased vibrations using frequency spectrum only, sometimes it is necessary to confirm present failure by some other characteristic (waveform, orbit, phase, etc.), by optical observing (opening bearing or coupling) or by physical measurement (misalignment by dials or laser, housing-foundation gap, etc).

\section{VIBRATION MEASUREMENT ON THE VENTILATION SYSTEM}

Vibration analysis and repair process for the ventilation system in thermal power plant is shown below.

Ventilation system equipment have properties shown in Table 1.

Table 1. Ventilation system equipment properties

\begin{tabular}{|c|l|}
\hline System name & Smoke drain ventilator (right) \\
\hline Manufacturer & "Vemos" Ltd., M. Bistrica, Croatia \\
\hline Motor serial no. & D-CV-09-100-1 \\
\hline Power & $1080 \mathrm{~kW}$ \\
\hline RPM & $990 \mathrm{RPM}$ \\
\hline No. of vanes & 8 \\
\hline $\begin{array}{c}\text { Ventilator } \\
\text { diameter }\end{array}$ & $2500 \mathrm{~mm}$ \\
\hline Shaft lenght & $5400 \mathrm{~mm}$ \\
\hline Shaft diameter & $440 \mathrm{~mm}$ \\
\hline Journal diameter & $160 \mathrm{~mm}$ \\
\hline Type of bearing & $\begin{array}{l}\text { Double row cylindrical roller } \\
\text { bearing }\end{array}$ \\
\hline
\end{tabular}

Ventilation system is shown in Fig.1.

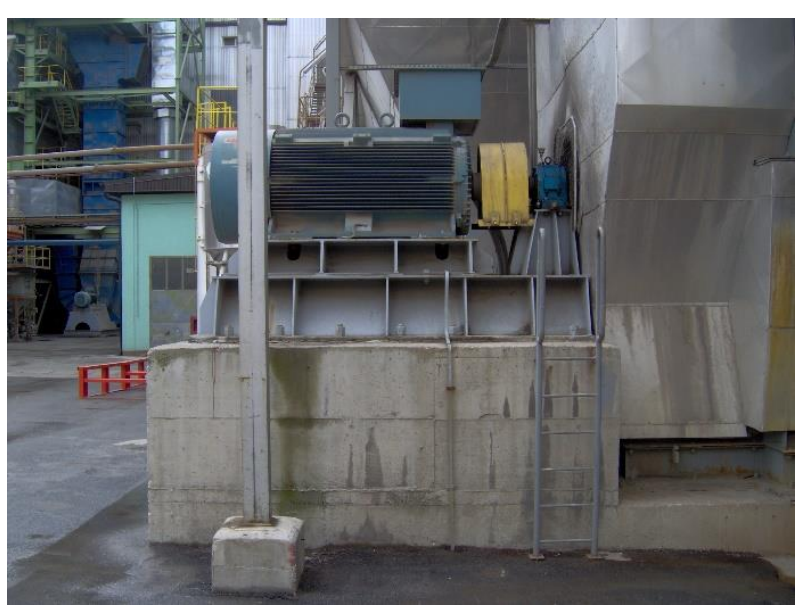

Fig.1. Motor flexibly coupled with ventilator

\subsection{Location and equipment used for vibration measurements}

Vibrations are measured on the housings of the motor and the ventilator bearings in three perpendicular directions: horizontal, vertical and axial. Measurements are marked with L1 and L2 for ventilator bearings, and $\mathrm{L} 3$ and $\mathrm{L} 4$ for motor bearings. Accelerometers of type KD $37 \mathrm{~V}$ and KD $41 \mathrm{~V}$ are used for measurements. Accelerometers are connected to Spider 8 device for data acquisition through M28 power supply. Spider 8 is then connected to the computer, which is used for data recording. Magnetic stands with screws are used for accelerometer mounting on housings, so it is easy to detach them after measuring.

Locations of bearings where measurements are done are shown on Fig.2.

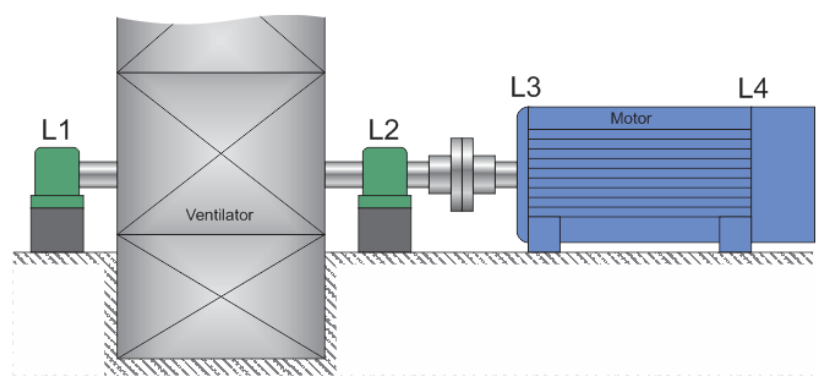

Fig.2. Names of measurement locations

Equipment used for data acquisition and measurement recordings is shown on Fig.3, and measurement scheme is shown on Fig.4. 


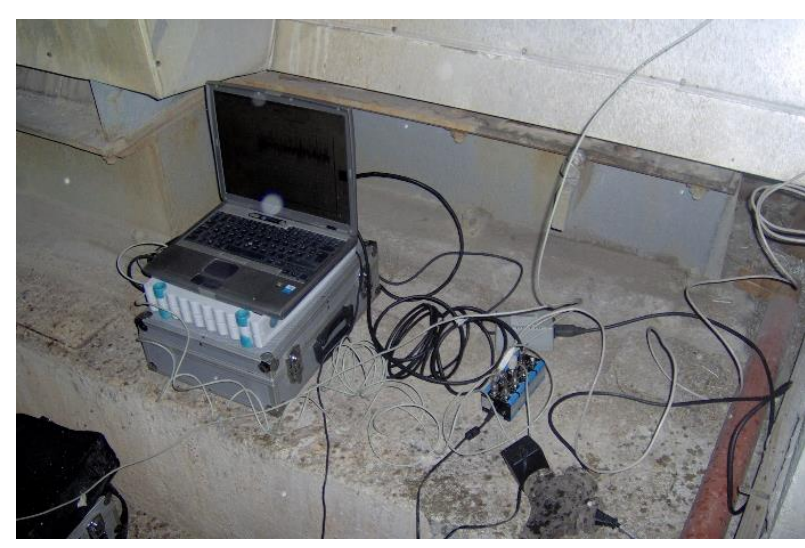

Fig.3. Computer, Spider 8 and M28 power supply

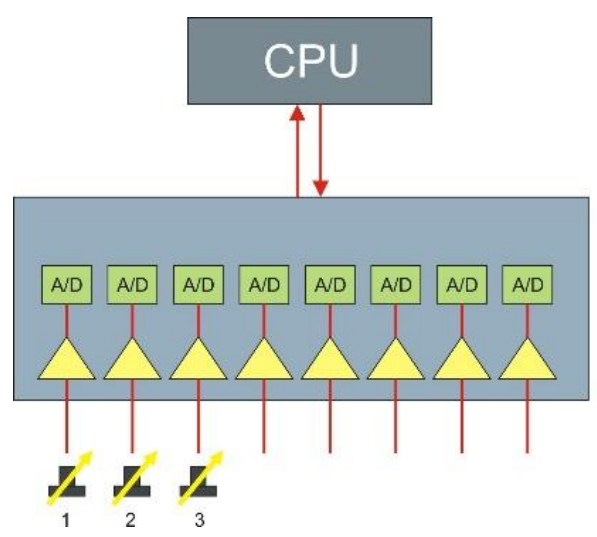

Fig.4. Measurement scheme

On Fig. 5 is shown one of the bearing housings with accelerometers attached to the measuring spots.

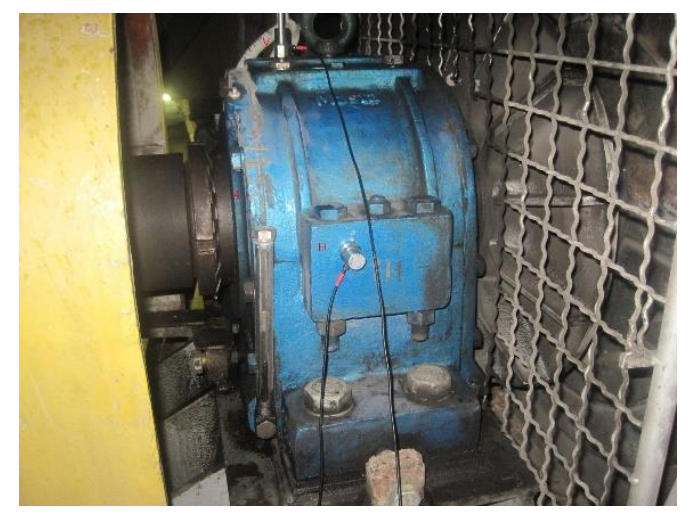

Fig.5. Bearing housing with accelerometer attached

\subsection{Operating modes of ventilation system used for vibration measurements}

Vibration testing program is planned to be done with different operating modes of the ventilation system. Operation modes for testing are chosen to be different number of rotations per minute of the ventilator shaft. Operation modes for vibration measurements are shown in Table 2.

Table 2. Operation modes for vibration testing

\begin{tabular}{|c|c|}
\hline $\begin{array}{c}\text { Measurement } \\
\text { number }\end{array}$ & RPM \\
\hline M1 & 410 \\
\hline M2 & 481 \\
\hline M3 & 547 \\
\hline M4 & 705 \\
\hline
\end{tabular}

\subsection{Result of vibration measurement}

Recorded acceleration data is integrated to obtain velocity records, which is used to calculate RMS of velocity. Results of the calculated RMS of velocity of ventilator bearings are shown in Table 3, and RMS of velocity of motor bearings are shown in Table 4

Table 3. RMS of velocity on ventilator bearings

\begin{tabular}{|c|c|c|c|c|c|c|}
\hline \multirow{2}{*}{ RPM } & \multicolumn{3}{|c|}{ L1 RMS [mm/s] } & \multicolumn{3}{c|}{ L2 RMS [mm/s] } \\
\cline { 2 - 7 } & H & V & A & H & V & A \\
\hline 410 & 1.7 & 0.5 & 0.2 & -- & -- & -- \\
\hline 481 & 2.1 & 0.7 & 0.5 & -- & -- & -- \\
\hline 547 & 4.7 & 3.0 & 0.5 & -- & -- & -- \\
\hline 705 & 6.1 & 1.0 & 2.1 & 11.2 & 9.3 & 3.6 \\
\hline
\end{tabular}

Table 4. RMS of velocity on motor bearings

\begin{tabular}{|c|c|c|c|c|c|c|}
\hline \multirow{2}{*}{ RPM } & \multicolumn{3}{|c|}{ L3 RMS [mm/s] } & \multicolumn{3}{c|}{ L4 RMS [mm/s] } \\
\cline { 2 - 7 } & H & V & A & H & V & A \\
\hline 705 & 5.1 & 3.9 & 3.2 & 5.3 & 1.9 & 3.0 \\
\hline
\end{tabular}

As it could be seen, levels of velocity RMS is high on all of measuring points. According to ISO 10816, with $705 \mathrm{rpm}$ machine is graded as class $D$ (vibration could cause damage), since its $11,2 \mathrm{~mm} / \mathrm{s}$ for horizontal and $9,3 \mathrm{~mm} / \mathrm{s}$ for vertical measurement on L2 (bearing closer to coupling). Rest of the RMS values are graded as class $C$ (short term operation allowable) according to ISO 10816, since its values are exceed $4,5 \mathrm{~mm} / \mathrm{s}$ which is lower limit for this class. It is required to determine what is the main cause of this increased vibrations. 


\section{VIBRATION ANALYSIS}

\subsection{Vibration analysis}

Recorded acceleration data is 43 nalysed by its waveform characteristics. On Fig. 6 and 7 are shown waveforms for bearings $\mathrm{L} 1$ and $\mathrm{L} 2$ on the ventilator.

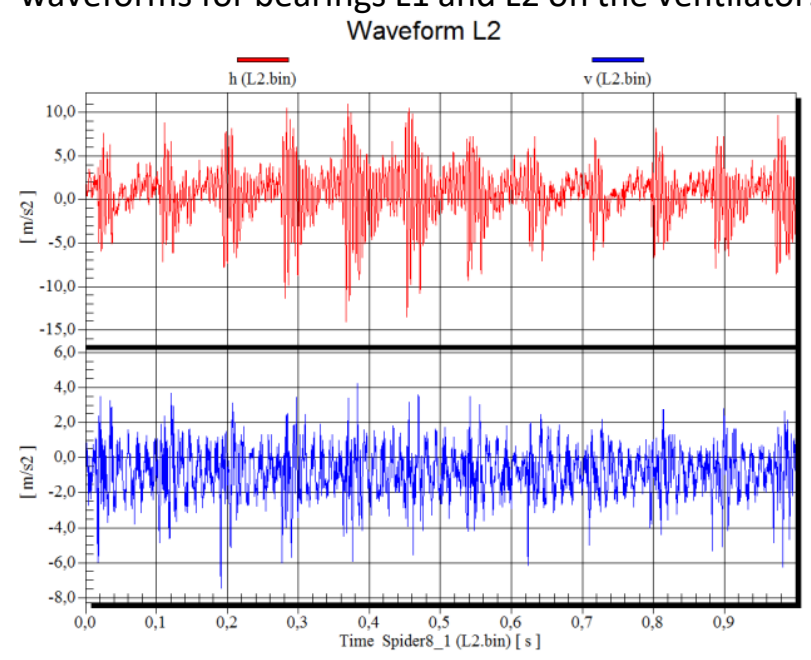

Fig.6. Waveform of acceleration for $\mathrm{L} 2$ ( $\mathrm{H}$ and $\mathrm{V})$

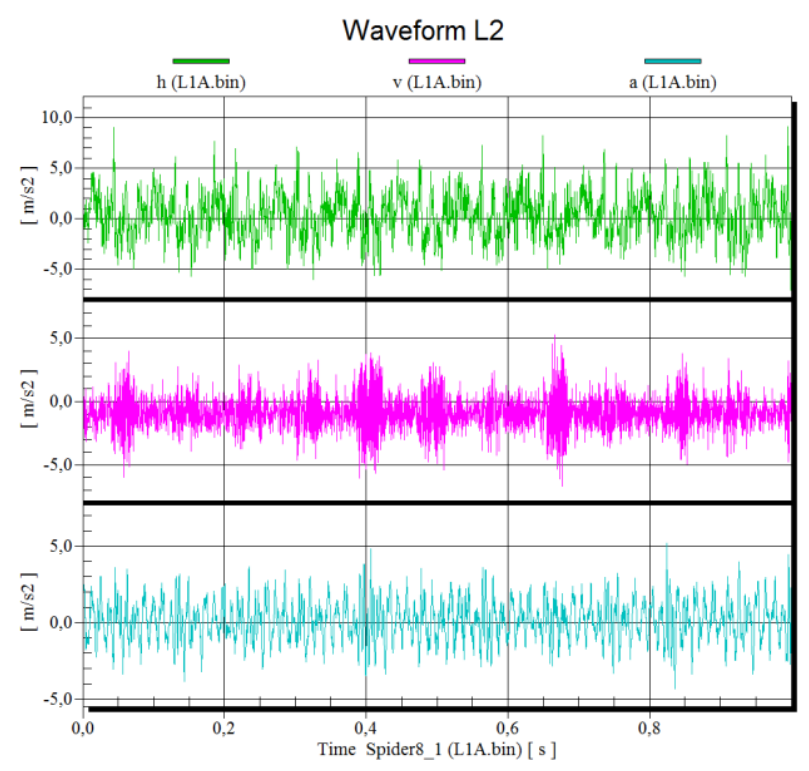

Fig.7. Waveform of acceleration for $L 1(H, V$ and $A)$

On the waveform for horizontal and vertical direction on bearing L1 some impacts could be noticed, which also transfers to horizontal direction on bearing L2. The shape of letter $\mathrm{M}$ and $\mathrm{W}$ could be also noticed on the waveform for horizontal direction of bearing $\mathbf{L 2}$. Those characteristics could suggest that combination of misalignment and looseness could be main faults of this system.

\subsection{Frequency spectrum analysis}

From the recorded accelerograms, frequency spectrums are created. On Fig. 8 and Fig. 9 are shown accelerograms for measurements done on ventilator bearings $L 1$ and $L 2$ in range from $0 \mathrm{~Hz}$ to $800 \mathrm{~Hz}$ when ventilator had $705 \mathrm{rpm}$.

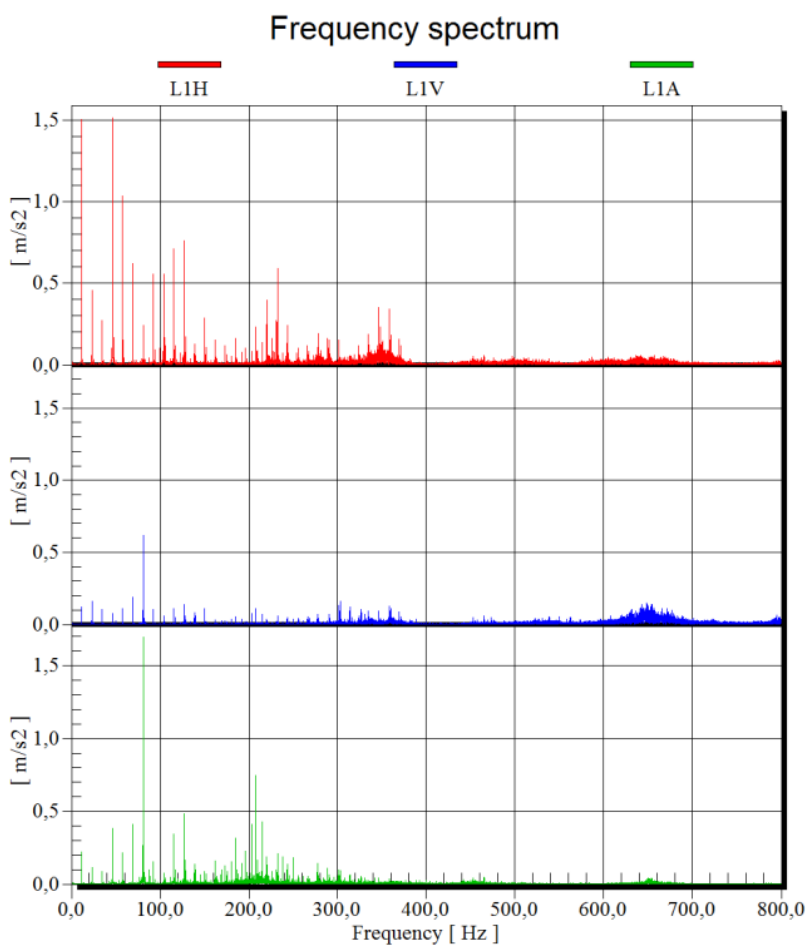

Fig. 8. Frequency spectrum of $L 1$ acceleration $(0-800 \mathrm{~Hz})$

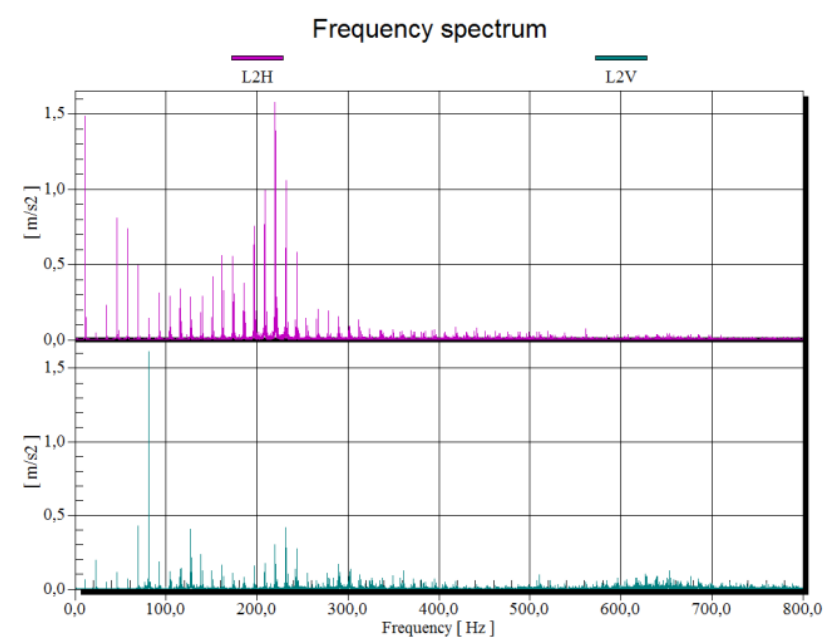

Fig.9. Frequency spectrum of $L 2$ acceleration $(0-800 \mathrm{~Hz})$

On frequency spectrums rotating frequency and its multiple orders are noticeable. It could be also noticed some nonsynchronous frequencies $(226 \mathrm{~Hz}$, $346 \mathrm{~Hz}$ ) where some of them could be bearing frequencies. Some floor noise is raised for frequency spectrum measured on the L1 bearing. Frequency spectrum characteristics shown on Fig. 8 and 9 are suggesting that possible cause of high 
vibrations is misalignment and looseness, which already caused bearing failure.

\section{REPAIR PROCESS}

After main failure is determined, repair process is planned to be done as soon as there is no request for the continuous machine operation. Since that stopping is planned in a few weeks, it is needed to decrease level of vibrations so operation of ventilation system is possible.

First step was to decrease misalignment level, Fig.10. During misalignment measurement, it is noticed that the ventilator shaft journal is radially moving inside bearing closer to the coupling. By measuring radial movement of shaft on both sides of bearing it is concluded that ventilator shaft journal is bent.

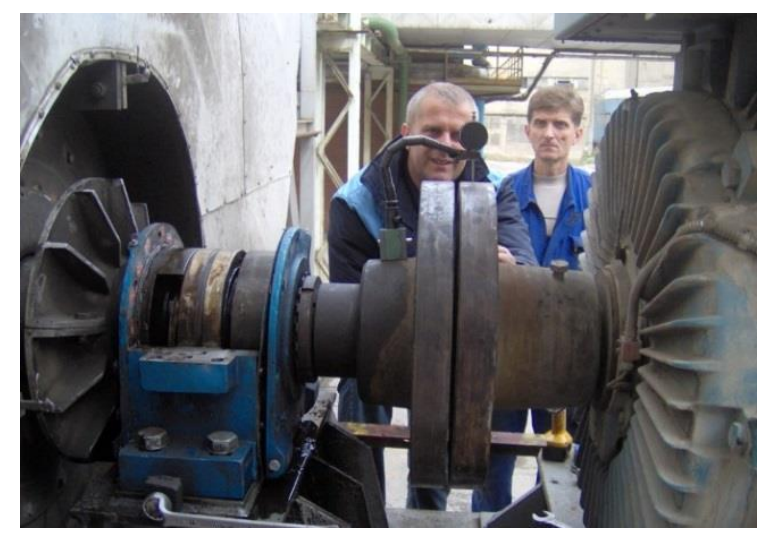

Fig.10. Misalignment measurement on coupling

On the coupling of ventilator shaft side is measured that shaft journal is $1 \mathrm{~mm}$ bent on that end of shaft. It is concluded that best solution is to distribute that $1 \mathrm{~mm}$ of bent shaft journal on 0,5 $\mathrm{mm}$ on each sides of motor shaft. Aligning procedure is done with radial and angular measurement (edge - face), where angular misalignment is reduced to $<0,05 \mathrm{~mm}$ per $100 \mathrm{~mm}$ length, and radial misalignment is distributed horizontally and vertically by $0,5 \mathrm{~mm}$.

\subsection{Vibration measurement after the quick repair process}

After alignment is done, ventilator and motor shafts are coupled. Vibrations on same locations are measured and compared with previous results. Velocity RMS values of vibrations after repair process are shown in Table 5.
Table 5. RMS of velocity on ventilator bearings after the quick repair process

\begin{tabular}{|l|l|l|l|l|l|l|}
\hline \multirow{2}{*}{ RPM } & \multicolumn{2}{|l|}{ L1 RMS $[\mathrm{mm} / \mathbf{s}]$} & \multicolumn{3}{l|}{ L2 RMS [mm/s] } \\
\cline { 2 - 7 } & H & V & A & H & V & A \\
\hline 200 & 0.8 & 0.2 & 0.2 & 0.7 & 0.3 & 0.5 \\
\hline 273 & 1.4 & 0.2 & 0.5 & 1.8 & 0.4 & 1.1 \\
\hline 365 & 1.8 & 0.4 & 0.5 & 1.5 & 0.6 & 1.9 \\
\hline 456 & 4.1 & 0.5 & 1.5 & 3.6 & 0.7 & 2.6 \\
\hline 548 & 2.4 & 0.4 & 0.8 & 2.5 & 3.2 & 3.9 \\
\hline 640 & 4.6 & 1.0 & 1.3 & 2.4 & 1.3 & 1.3 \\
\hline 686 & 4.4 & 1.1 & 1.4 & 2.3 & 1.3 & 1.8 \\
\hline
\end{tabular}

As it could be seen, highest value of vibrations on bearing $L 1$ is decreased from $6.1 \mathrm{~mm} / \mathrm{s}(705 \mathrm{rpm})$ to $4.6 \mathrm{~mm} / \mathrm{s}(686 \mathrm{rpm})$, and for bearing $\mathrm{L} 2$ is decreased from $11.2 \mathrm{~mm} / \mathrm{s}$ (705 rpm) to $3.6 \mathrm{~mm} / \mathrm{s}$ (456 rpm). This drastic reduce of the vibration levels are due to distribution of ventilator bent shaft on both sides of motor shaft.

On Fig.11 are shown levels of measured vibrations before and after the repair process. This ventilation system belongs to group 1 of machines with nominal power greater than $300 \mathrm{~kW}$ and with rigid foundations.

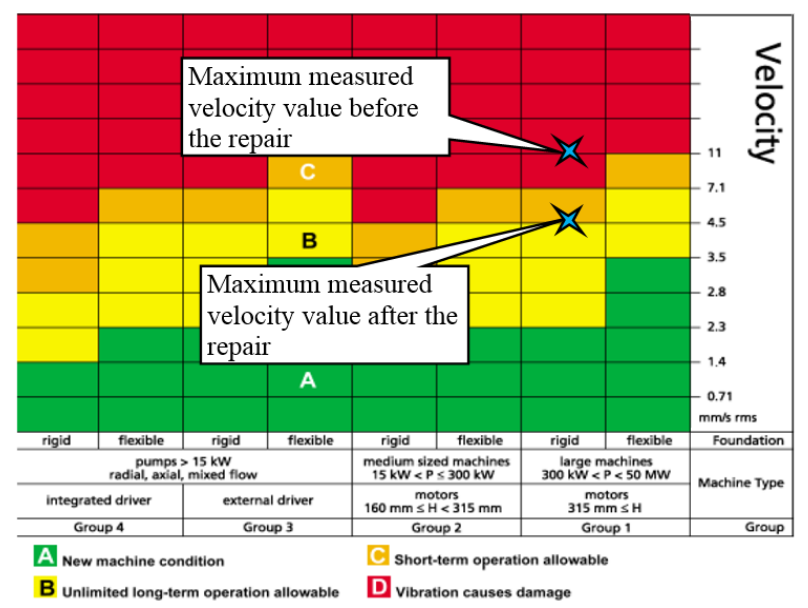

Fig.11. Vibration grade according to ISO 10816 before and after the quick repair process

As it could be seen, before quick repair process, maximum vibration level was larger than $7,1 \mathrm{~mm} / \mathrm{s}$ which is lowest value of class $D$, where vibration could cause damage. After the quick repair process, highest value of vibrations was just above the 4,5 $\mathrm{mm} / \mathrm{s}$, which is satisfying class $C$, which allows short-term operation. According to ISO 10816, ventilation system is operable until it is possible to start its main reparation process. 


\subsection{Vibration measurement after the main repair process}

Main repair process started after the few weeks. Ventilator was disassembled and shaft and bearings were examined. It is determined that shaft journal was bent on its end closer to coupling. Since it was bent, it damaged the bearing closer to the coupling and shaft journal was slipping inside. This could be seen on Fig.12, where traces of slipping are visible on bearing inner ring.

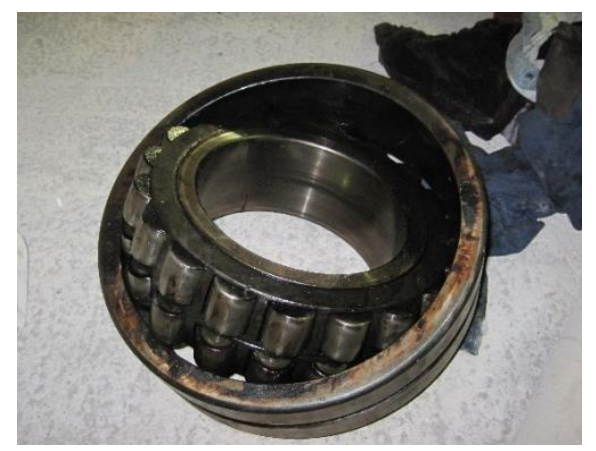

Fig.12. Visible traces of skidding on inner ring

Similar traces are visible also on journal where this bearing was mounted. Most possible scenario in this case was that shaft mounted on ventilation system was already bent. Because of that, bearing was loaded over its maximum force and journal grinded inside inner ring of bearing and made some gap, so journal could skid inside the bearing. Since shaft was bent, it acted similar as misalignment. And since it made some gap between journal and bearing inner circle, it also had some frequency spectrum characteristics similar to misalignment frequency spectrum. Velocity RMS values after the main reparation process is shown in Table 6 .

Table 6. RMS of velocity on ventilator bearings after main repair process

\begin{tabular}{|c|c|c|c|c|c|c|}
\hline \multirow{2}{*}{ RPM } & \multicolumn{2}{|c|}{ L1 RMS [mm/s] } & \multicolumn{3}{c|}{ L2 RMS [mm/s] } \\
\cline { 2 - 7 } & H & V & A & H & V & A \\
\hline 200 & 0.2 & 0.0 & 0.1 & 0.1 & 0.1 & 0.1 \\
\hline 273 & 0.2 & 0.0 & 0.2 & 0.1 & 0.1 & 0.2 \\
\hline 365 & 0.3 & 0.1 & 0.4 & 0.3 & 0.0 & 0.3 \\
\hline 456 & 1.2 & 0.2 & 0.6 & 1.5 & 0.2 & 0.7 \\
\hline 548 & 0.8 & 0.2 & 1.0 & 1.3 & 0.2 & 0.7 \\
\hline 640 & 1.6 & 0.4 & 1.4 & 1.3 & 0.5 & 1.1 \\
\hline 731 & 1.8 & 0.5 & 2.1 & 1.7 & 0.5 & 1.7 \\
\hline
\end{tabular}

After the main reparation process where shaft and bearings are changed with new parts, vibrations are measured. It is shown that all vibration levels are classified as $A$, which is stated as a new machine condition.

\section{CONSLUSIONS}

After this presented analysis, some conclusions could be stated as follows:

- If there are characteristics of vibrations which are similar for some different faults, it is sometimes required to take physical measurements of some possible faults to have full picture of what is happening in the machine.

- It is possible to reduce vibrations on the machine by reducing one of the faults which caused vibrations.

- $\quad$ Reducing machine vibrations should make machine operative, at least until it is possible to fully repair the machine.

According to ISO 10816 levels, after the quick repair it is recommended to work with $60 \%$ capacity $(550 \mathrm{rpm})$ until the main reparation process is possible.

- The main repair process has removed sources of the increased vibrations, so there are no restrictions for operating with this system after the main repair process.

\section{REFERENCES}

[1] J. Piotrowski, Shaft Alignment Handbook, third ed., Taylor and Francis Group, Boca Raton, 2007.

[2] M. Friswell, Models for the condition monitoring of rotating machinery. Proceedings of the International conference "Condition Monitoring", Cambridge, UK, 2005, pp.385392.

[3] M. Xu, R. D. Marangoni, Vibration analysis of a motor-flexible coupling-rotor system subject to misalignment and unbalance, part I: theoretical model and analysis. Journal of Sound and Vibration, 176 (5), 1994: 663-679.

https://doi.org/10.1006/jsvi.1994.1405

[4] E. Nezirić, S. Isić, V. Doleček, I. Karabegović, Vibration analysis of theoretical SDOF model of shaft parallel misalignment. Journal Technology, 5 (4), 2013: 131-134.

[5] X. Li, The analysis of vibration fault features and vibration mechanism caused by Rotating machinery loosening. Advanced Materials Research, 518-523 (-), 2012: 3826-3829.

https://doi.org/10.4028/www.scientific.net/AMR.518 -523.3826

The shorter version of this research was presented at the "8nd International Scientific Conference IRMES 2017", 7 - 9 September 2017, Trebinje, Bosnia and Hercegovina. 